Volume: 1, Issue: 4, December 2016, Pages: 98-99, DOI: http://dx.doi.org/10.19082/ah98

\title{
HOW TO WRITE A BETTER CASE REPORT
}

\author{
Pouria Yazdian
}

M.D., Student Research Committee, Shahid Sadoughi University of Medical Sciences, Yazd, Iran

\section{TYPE OF ARTICLE: LETTER TO EDITOR}

\begin{abstract}
This short letter to the editor provides ideas on how to write and organize a case report article in the areas of medical research.

KEYWORDS: Case report, Medical journal, Scientific writing
\end{abstract}

\section{Dear Editor,}

Case reports have an important impact on medical education and research; thus, case reports are the main foundation of future research (1). In the last month, I was reading some new cases and helping my friend to write his own case reports, but I saw that this case report had some important structural defects. Due to my experience, I feel we need to review our knowledge in writing case reports; in this paper, I'm going to review "How to write a better case report." A case report has six main parts: Title, Abstract, Introduction, Case Presentation, Discussion, and Conclusion (2). First, we should use a short and brief title that shows the main purpose of presentation; in the end of title, we should use ": case report" (3). As the author guidelines of your chosen journal are considered, you have to choose a structure for your abstract, but we have to include these parts in a good abstract: 1) A brief introduction about our case and why it's novel. The introduction should be three or four sentences and no more. 2) In the next part you have to introduce your case in five to seven sentences. In the first sentence, we have to introduce our patient, including gender, age, and main problem of the case. After that, note the treatment and follow-up of the patient; the outcome of the treatment also should be considered (treat, death, or recurrence). 3) In this part, we have to conclude our case presentation. We have to place emphasis on the patient's diagnosis, treatment, and outcome.

For the introduction, we should introduce our case in one paragraph and not any more. In this paragraph, in the first two or three sentences, the main finding of the case should be described. For the second sentence, we have to describe the novelty of the case presentation. In this part, we should note how many articles we found similar to this article and the cause of novelty. In the last sentence, the aim of this article should be considered (4). The main part of a case report is here; case presentation describes how the case is presented to the patient. First of all, it's important to describe the demographic characteristic of the patient in one or two sentences; after that, the patient's chief complaint is the next part of the case report. After that comes the diagnosis of the disease: It should be purposive and without any gloss. This part should have the useful graphs and diagnostic materials. Treatment of the patient is one of the important parts of a case report, you should respectively mention its treatment and the outcome (2). Anything you want to say is here: What happened? Why you did that? The first part of discussion should emphasize the main aspect of the case report. After the first paragraph, you have to discuss the other important parts of the case report. In the discussion, you have to compare your case and your approach to the patient with other cases and other papers in the field of the report. In this part, you can use a table, which consists of all the cases that were similar to your case report (3). This is the last part, write it carefully; sometimes it's only the first part that a researcher will read. You have to answer "Know what?" "What did you learn from this case?" "Is the diagnosis important or the treatment or how you follow-up with the patient?" Last, I highly recommend that you use a Care

\section{Correspondence:}

Dr. Pouria Yazdian, Shahid Sadoughi University of Medical Sciences, Yazd, Iran. Tel: +98.9385101025, E-mail: pouria_yazdian_a@yahoo.com.

Received: March 1, 2016, Accepted: September 13, 2016, Published: December 2016

iThenticate screening: March 11, 2016, English editing: September 23, 2016, Quality control: September 29, 2016

(C) 2016 The Authors. This is an open access article under the terms of the Creative Commons Attribution-NonCommercialNoDerivs License, which permits use and distribution in any medium, provided the original work is properly cited, the use is non-commercial and no modifications or adaptations are made. 
Checklist; it's a good idea for transparency and data analysis in case reports and is as a good way to properly write the case reports (5).

\section{CONFLICT OF INTEREST:}

There is no conflict of interest to be declared.

\section{REFERENCES:}

1) McCarthy LH, Reilly K. How to write a case report. Family Medicine. 2000; 32(3): 190-5. PMid: 10726220.

2) Ghadiri-Sani M, Larner A. How to write a case report. British Journal of Hospital Medicine. 2014; 75(4): 207-10.

3) Green BN, Johnson CD. How to write a case report for publication. Journal of Chiropractic Medicine. 2006; 5(2): 72-82. doi:10.1016/S0899-3467(07)60137-2.

4) Gurudatt CL. Case reports: Brief overview of reporting and submission to biomedical journal. Indian J Anaesth. 2016; 60(9): 695-699. doi: 10.4103/0019-5049.190629. PMid: 27729700. PMCid: PMC5037954.

5) Khalil S, Mishra D. Sharing clinical experience with the scientific community: How to write a case report? Indian pediatrics. 2016; 6(53): 513-6. PMid: 27376606. 